\title{
Ambivalence Towards Childbirth in a Medicalized Context:A Qualitative Inquiry Among Iranian Mothers
}

\author{
Sedigheh Sedigh Mobarakabadi ${ }^{1}$; Khadijeh Mirzaei Najmabadi ${ }^{1, *}$; Mahmoud Ghazi \\ Tabatabaie $^{2}$ \\ ${ }^{1}$ Department of Nursing and Midwifery School, Mashhad University of Medical Sciences, Mashhad, IR Iran \\ ${ }^{2}$ Department of Demography and Population Studies, University of Tehran, Tehran, IR Iran \\ *Corresponding Author: Khadijeh Mirzaei Najmabadi, Department of Midwifery, Mashhad University of Medical Sciences, Avicenna Street, Mashhad, Khorasan Razavi Province, IR \\ Iran. Tel: +98-5138598016, Fax: +98-5138598016, E-mail: mirzaeikh@mums.ac.ir
}

Received: September 30, 2014; Revised: November 18, 2014; Accepted: December 9, 2014

\begin{abstract}
Background: Today, pregnant women are treated as individuals requiring medical care. Every day, more and more technologies, surgical procedures and medications are used even for low-risk childbirths. These interventions can save mothers' lives in threatening situations, although they might be risky for mothers and neonates in low-risk deliveries. Despite the increasing interest in medical care for childbirth, our knowledge about underlying factors for development of medicalized childbirth is limited in Iran.

Objectives: The purpose of this study was to provide a broad description of medicalized childbirth in Iran.

Materials and Methods: In this study, a qualitative approach was applied and data was gathered via in-depth interviews. The subjects were selected via purposive sampling. Overall, 27 pregnant and postpartum women were enrolled in this study. Participants were selected from public health centers, hospitals and offices. Data analysis was performed using conventional qualitative content analysis.

Results: As the results indicated, mothers preferred medicalized childbirth under the supervision of obstetricians. The subjects mostly opted for elective cesarean section; this choice led to an increase in physicians' authority and restricted midwives' role in childbirth. Consequently, mothers' preference for cesarean section led to the expansion of medicalization and challenged the realization of natural childbirth. Mothers also had a strong tendency toward natural childbirth.

Conclusions: Generally, many Iranian mothers choose the medicalized approach, despite their inclination to comply with the natural mode of delivery. It seems that mothers have an ambivalent attitude toward childbirth. Health authorities can prevent the adverse effects of medicalized birth and encourage natural childbirth among women using the obtained findings.
\end{abstract}

Keywords:Childbirth; Iran; Medicalization; Qualitative Research

\section{Background}

In the past few decades, significant progress has been made in improving maternal health worldwide. The number of women giving birth at healthcare facilities has increased in many regions (1). Globally, maternal mortality rate has been decreased from 400 deaths in 1990 to 210 deaths per 100000 in 2010 (2).

Advances in maternal care and significant reduction in maternal mortality led to the medicalization of childbirth (3). Medicalization is described as a process through which non-medical issues such as low-risk childbirth are treated as medical concerns (4). In fact, medical interventions for the management of pregnancy- or childbirth-related complications can save people's lives. However, using these procedures in normal situations can be costly and risky for mothers and neonates. These procedures can also influence the social construction of childbirth and maternity care $(5,6)$.

In a medicalized context, pregnant women are treated as individuals requiring medical care. This attitude leads to an increased reliance on healthcare professionals and expansion of physicians' authority in the management of childbirth (7).

For a medicalized childbirth, more and more technologies, surgical procedures and medications are used even for low-risk childbirths (3). In the USA, childbirth was the most common cause of hospitalization in 2006; also, more than $50 \%$ of childbirths involved medical induction. In addition, artificial rupture of membranes and fetal monitoring were performed in $23.7 \%$ and $22.5 \%$ of childbirths, respectively (8). In fact, the rate of cesarean section (c-section) has been increased over the past decade in the USA (9). Similarly, studies in the Netherlands showed an increasing interest in using medical interventions for natural delivery. Moreover, increasing use of epidural analgesia, labor induction and labor augmentation have been reported (6).

Medicalization of childbirth is not limited to developed countries and medicalized maternity care is provided 
in developing countries as well (3). Iran as a developing country, has made great advances in maternity care and maternal mortality reduction (10); these advances have been accompanied by childbirth medicalization. A study in Iran reported that only $35 \%$ of deliveries are performed by midwives, while $65 \%$ of childbirths are performed by obstetricians; also, 93\% of mothers were admitted to hospitals before the initiation of labor pain (11).

The rate of c-section is quite high in urban and rural regions of Iran. In Iran, c-section rates were reported to be $38.4 \%, 45 \%$ and $47.9 \%$ in 2005, 2007 and 2009 , respectively. While the rate of c-section was $74.3 \%$ in Tehran (the capital of Iran) (12), in some poor regions, mothers still gave birth at home by the help of traditional birth attendants. In these cases, medical intervention for child delivery was perceived risky by these women (13).

Iran Ministry of Health has its own specific structure and healthcare is provided by several sources. In Iran, governmental and university centers, as well as hospitals, provide free or low-cost medical care. In addition, several health insurance companies cover different levels of medical care with various costs and private sector controls medical care in offices and hospitals. Moreover, a number of other organizations offer medical care for their employees (14).

Although various studies have shown an inclination toward medicalized childbirth in Iran, these studies have mainly focused on specific parts of medicalization (11, 12, 15). Therefore, our knowledge about underlying factors for the development of medicalized childbirth is limited in Iran. Moreover, different maternity care models, payment systems and attitudes toward obstetric care provide a specific context for medicalization of childbirth in our country. Considering these differences, a broad description of medicalized childbirth can be useful for designing health policies for low-risk child births.

\section{Objectives}

To identify the underlying factors for the spread of medicalized childbirth, we aimed to provide a broad description of medicalized childbirth in Iran, based on women's perspectives.

\section{Materials and Methods}

\subsection{Approach}

In the current study, a qualitative approach was applied. This methodological approach focuses on understanding, description and interpretation of a phenomenon as perceived by individuals (16). In this approach, investigators have the ability to describe a phenomenon from the perspective of individuals with related experiences (17).

In a qualitative approach, data analysis is performed using different methods (18) including qualitative content analysis. Hsieh and Shannon described three methods for qualitative content analysis including conventional analysis. This design allows researchers to immerse themselves in data to attain new insights about a phenomenon when their knowledge is limited; as a result, categories are developed from data, not from preconceived categories (19). Therefore, a conventional qualitative content analysis can provide a broad description of medicalized childbirth in Iran.

\subsection{Sample Recruitment}

Twenty-seven pregnant and postpartum (who had experienced childbirth 1-10 days prior to the study) women participated in the current study. Participants were selected from Mashhad, the capital of Khorasan Razavi province, Iran.

Purposive sampling was applied to gather a broad range of data. In this type of sampling, participants are selected based on a set of criteria (16). The main inclusion criteria in our study were as follows: 1) being a pregnant or postpartum mother; 2) having a low-risk pregnancy and childbirth; 3 ) receiving prenatal care from obstetricians or midwives; 4 ) giving birth at a governmental or private hospital; and 5) experience of natural delivery or cesarean section.

We used maximum variation of demographic and socio-economic characteristics including subjects' age, education level, occupational status, housing status and insurance/supplemental insurance status. Women with high-risk pregnancies or childbirths (e.g. preeclampsia, diabetes, urinary tract infection, preterm labor and chronic diseases) were excluded from the study. Thirtytwo women were enrolled inthe study; four women were excluded due to high-risk pregnancy and one woman withdrew from the study because of time limitation. Participants were selected from public healthcare centers, hospitals and private sectors of Mashhad, Iran.

\subsection{Data Collection}

Data was gathered via in-depth, unstructured interviews at public healthcare centers, hospitals and participants' houses. The interviewer was a member of the research team with comprehensive knowledge about qualitative research and previous experience of working with pregnant and postpartum women. Interviews took 50 to 80 minutes and the focus of interview questions was on participants' understanding of childbirth, i.e., their perceptions of childbirth; further questions were based on participants' responses. All interviews were audio-recorded, transcribed verbatim and analyzed. Data collection continued until we reached the point of data saturation (20).

\subsection{Ethical Considerations}

This study was approved by the ethics committee of Mashhad University of Medical Sciences, Mashhad, Iran (ethical approval code: 511/2944). Permission to access participants was sought from the deputy director of 
health at Mashhad University of Medical Sciences, chairman of the hospital and head of nursing.

Written informed consents were obtained from the participants before conducting the interviews. The interviewees were able to withdraw from the study at any point and all tapes and transcripts were kept anonymous for the confidentiality of data. All information sheets, tapes and transcripts were given special codes to guarantee participants' anonymity.

\subsection{Data Analysis}

To derive the main themes and categories, qualitative content analysis, designed by Graneheim and Lundman was used (21). The whole interview was selected as the unit of analysis. Data analysis was started by reading all interviews repeatedly to achieve data immersion and identify the meaning of units. Then, the meaning units were condensed to derive the codes. The obtained codes were sorted into subcategories and the subcategories with shared meanings were grouped into categories. The final themes were developed by linking the underlying meanings together in categories.

Data was analyzed using MAXqda (potable 2007, Udo Kuckartz Berlin/Germany ). To improve the trustworthiness of the research, interviews were analyzed by two members of the research team to attain credibility. All the analyses were checked to find similarities and points of conflict. Conflicts were checked by another member of the research team.

A part of the transcripts and codes was presented to some participants for confirmation or adding comments to ensure depend ability and confirm ability. Two mothers not participated in the study, were asked to review the transcripts and codes to improve its transferability (21, 22).

\section{Results}

In this study, 27 pregnant and postpartum women, aged 20-35 years, were interviewed. The subjects' characteristics are presented in Table 1. Quotes are shown in italics. Pregnant and postpartum subjects are identified with $P$ and P.P after quotations, respectively.

Ambivalence toward childbirth was the main derived theme. According to the analysis of data, women's attitude towards childbirth was ambivalent. Mothers were not sure whether they wanted natural birth; they had the same attitude toward c-section. On one hand, they advocated the medicalization of childbirth and its benefits and on the other hand, they were willing to undergo natural childbirth.

Finally, three categories emerged as follows; "Expansion of medicalization, given the high prevalence of elective c-section", "natural childbirth challenges in medicalized contexts" and "challenges of medicalization considering women's preference for natural birth". These categories are explained further in the following sections.

\begin{tabular}{|c|c|}
\hline Characteristics & Values \\
\hline \multicolumn{2}{|l|}{ Women's status } \\
\hline Pregnant & $14(51.85)$ \\
\hline Postpartum & $13(48.14)$ \\
\hline \multicolumn{2}{|l|}{ Parity } \\
\hline Primiparous & $17(62.96)$ \\
\hline Multiparous & $10(37.03)$ \\
\hline \multicolumn{2}{|l|}{ Educational level } \\
\hline Elementary & $4(14.81)$ \\
\hline Secondary & $9(33.33)$ \\
\hline Post-secondary & $10(37.03)$ \\
\hline Postgraduate & $4(14.81)$ \\
\hline \multicolumn{2}{|c|}{ Occupational status } \\
\hline Homemaker & $18(66.66)$ \\
\hline Employed & $9(33.33)$ \\
\hline \multicolumn{2}{|l|}{ Housing status } \\
\hline Rental housing & $17(62.96)$ \\
\hline Private housing & $10(37.03)$ \\
\hline \multicolumn{2}{|l|}{ Insurance } \\
\hline Yes & $22(81.48)$ \\
\hline No & $5(18.51)$ \\
\hline \multicolumn{2}{|c|}{ Supplemental insurance } \\
\hline Yes & $19(70.37)$ \\
\hline No & $8(29.62)$ \\
\hline
\end{tabular}

${ }^{\mathrm{a}}$ Data are presented as No. (\%).

\subsection{Expansion of Medicalization, Given the High Prevalence of Elective C-Section}

Participants' statements revealed that c-section has gained acceptance among women; in fact, women perceived c-section as the superior mode of childbirth. High prevalence of elective c-section reduced the number of natural births and considered a suitable mode of delivery for women:

"I prefer c-section. I think it is more acceptable of all young women that I know, none have chosen natural birth." (P3, primiparous, 30 years old)

As these women stated, families and relatives suggest csection as the suitable mode of delivery:

"My mother and sister-in-law suggested c-section." (P10, multiparous, 34 years old)

The participants' statements revealed that these women prefer c-section and some of them accept it as a natural phenomenon: "I think giving birth is a natural phenomenon; of course c-section not vaginal delivery.” (P5, primiparous, 31 years old)

Positive perceptions toward c-section, as a convenient mode of delivery, along with fear of natural birth contributed to the choice of c-section. This point can be summa- 
rized by a subject's remarks:

"I will go to the hospital at a specific time, I will be unconscious, and physicians would deliver my baby. Then, I will stay at the hospital for a night and come back home the day after. But when I think about vaginal delivery, I get scared." (P11, primiparous, 31 years old)

However, some women chose c-section to avoid unfavorable experiences of natural childbirth:

"My sister had a terrible experience, I was there (at the hospital), she could not do it, and she had to do a c-section. Now, she has a baby with a mental problem. I do not want to have the same experience." (P9, primiparous, 28 years old)

Participants believed that obstetricians, private hospitals and insurance companies encourage the prevalence of elective c-section. As the subjects stated, obstetricians suggest c-section to mothers and assure them about its safety; this leads to widespread use of c-section. As one of the participants remarked:

"My physician went on vacation during holidays; she introduced me to one of her colleagues to perform the c-section." (P13, multiparous, 34 years old)

Moreover, private hospitals support elective c-section by providing high-quality facilities for mothers. Supplemental insurance plans also encourage the prevalence of c-section. In this regard, one mother said:

"If you want to choose c-section, you have to choose private hospitals; you cannot do a c-section at governmental hospitals. If you pay more to private hospitals, they provide you with high-quality healthcare." (P.P7, multiparous, 29 years old)

\subsection{Natural Childbirth Challenges in Medicalized Contexts}

Medicalized contexts challenge the realization of natural childbirth. As participants declared, hasty decisions to have c-section and insufficient facilities for performing natural childbirth account for insufficient social support for natural birth:

"I do not want a natural delivery. If we had more specialized healthcare centers, supporting natural birth, I would have made a different decision." (P3, primiparous, 30 years old)

The participants believed that private hospitals provide inadequate support for performing natural delivery:

"At private hospitals, if a woman's pain continues for a few hours and she cannot deliver the baby, physicians immediately perform c-section." (P.P19, primiparous, 22 years old)

Changes in mothers' attitudes toward natural birth have negatively affected natural childbirth. In their opinion, child delivery is a difficult and painful experience. Mothers do not like the unpredictable nature of natural delivery:

"Delivery is a difficult experience. Maybe the pain starts at midnight or in a bad situation. It is a bad feeling; I do not like it." (P11, primiparous, 31 years old)

Application of therapeutic approaches (e.g. electronic fetal heart rate monitoring and changes in maternal positions) for childbirth is another change in natural delivery:

"They told me to lie on my back. I could not because it was too painful, but they forced me to do it because they wanted to check the baby's heart." (P.P6, primiparous, 21 years old)

Participants also mentioned changes in professional roles of midwives and obstetricians during childbirth. Midwives who used to manage natural birth, have lost their authority and faced challenges in realizing their responsibilities during natural delivery. Midwives who used to provide prenatal care at public healthcare centers, can no longer be actively involved in child delivery:

"Midwives provide prenatal care at public centers, but I have to choose a physician for delivery, since she (midwife) cannot perform it." (P.P12, multiparous, 32 years old)

Moreover, mothers do not trust the skills of midwives, who attend natural deliveries:

"I cannot even imagine a midwife doing my delivery; it should be performed by a physician. Maybe something happens and midwife cannot handle the situation." (P24, primiparous, 35 years old)

Since mothers trust obstetricians, they ask their attendance during child delivery. Obstetricians are not inclined to manage natural childbirths; therefore, they suggest mothers choose c-section during prenatal care. This point can be summarized by a subject's remarks:

"I wanted a natural delivery. I insisted on it during the prenatal visits. Myphysician said we would make a decision by the end of pregnancy, but in the end, she said she preferred c-section. I had no choice but to accept it." (P10, multiparous, 34 years old)

Mothers felt that they could not handle the delivery by themselves and asked for help of high-skilled health providers:

"I chose c-section. I liked natural birth but I was afraid I could not handle it. I need someone to help me.” (P3, primiparous, 30 years old)

According to the subjects' statements, husbands discourage mothers from performing natural childbirth:

"At first, my husband preferred natural delivery. After some time, he told me that my stomach was too big and I was too thin to undergo natural delivery." (P3, primiparous, 30 years old)

\subsection{Challenges of Medicalization Considering Women's Preference for Natural Childbirth}

Despite all challenges of performing natural childbirth in medicalized contexts, tendency toward natural birth has caused some challenges for medicalization of childbirth. The participants expressed their inclination towards natural birth:

"I like natural delivery. I prefer following the natural 
process." (P.P6, primiparous, 21 years old)

"I believe that what God chooses for us is the best. God chose natural birth, so it is the best way to do it." (P16, multiparous, 34 years old)

Some mothers chose natural childbirth so that they could be more in touch with the birth of their neonates:

"I would take the pain just to see my baby being born." (P25, multiparous, 26 years old)

Although some healthcare providers support the medicalization of childbirth, others including midwives and some obstetricians advocate natural childbirth:

"My physician suggested natural childbirth and informed me about its benefits. She said I was a good candidate for natural birth." (P19, primiparous, 26 years old)

In addition, some midwives, despite their limitations in performing child delivery, try to train mothers during pregnancy:

"The midwife told me about natural birth and its benefits and introduced some books on the subject. She said she could not do the delivery, because she had to work at a healthcare center, but she assured me that her colleagues working at hospital could help me with the delivery." (P26, primiparous, 35 years old)

\section{Discussion}

This study assessed the medicalization of childbirth in Iran. For an in-depth investigation, a qualitative method of inquiry was used and mothers' perspectives were evaluated. An ambivalent attitude toward medicalized childbirth was found.

Medicalization of childbirth is associated with expansion of elective c-section. In fact, high prevalence of elective c-section has led to the acceptance of medicalization among women. Elective c-section has turned into a norm in our society. Women's preference for c-section is influenced by cultural and social factors (23). For instance, in Southwest Nigeria, where natural childbirth is the prevalent mode of delivery, there is a widespread aversion to c-section, even in life-threatening situations (24). On the other hand, in many countries, as Walker et al. showed, women consider elective c-section as a convenient mode of childbirth (25).

A medicalized context cannot empower pregnant women for natural child delivery; therefore, they choose medicalized childbirth as a convenient mode of delivery. Indeed, endeavors in midwifery for empowering women are limited in disempowering contexts (26). Medicalization of childbirth creates an environment in which women lose control over their own bodies and decisions (3). In one study by Gamble and Creedy, women who preferred elective c-section, were poorly informed about the risks of c-section and overestimated its safety (27).

As elective c-section becomes more widespread, natural childbirth faces various challenges. It seems that these challenges result from the medicalization of childbirth and its reinforcement. Changes in perceptions of women and their expectations of natural childbirth are part of these challenges. Although many women consider childbirth as a natural process, they accept and often prefer a medicalized childbirth (28).

Medicalization is the result of reconceptualizing pregnancy as a medical condition; this reconceptualization leads to the acceptance of medicalized childbirth among women. Therefore, since women consider pregnancy and childbirth as health-related complications, their expectations and attitudes would change significantly (29).

Changes in the roles of midwives and obstetricians in natural birth were among other challenges of natural delivery. When childbirth is approached by medical ways of thinking, midwife's role in the process of childbirth changes (7). More importantly, medicalization changes people's perceptions of midwives' professional skills; therefore, obstetricians replace midwives in natural childbirth (29).

Despite the hegemonic medical view of birth and women's high acceptance of it, women's attitudes toward natural birth are ambivalent. As Wagner noted, "If more physicians experienced an earthquake or volcano, they would realize their ideas of controlling nature are nothing more than stories to rewrite insignificance" (3).

In British middle-class circles, women resist medicalization to preserve a sense of control and empowerment over their pregnancy and childbirth (30), since high levels of obstetric intervention may reduce women's ability to make informed decisions about childbirth (31).

In Iran, more than $99 \%$ of the population are Muslims (32) and women who give birth naturally are honored in the Islamic religion. According to Islamic beliefs, childbirth is a natural phenomenon approved by God (15). Therefore, despite the high acceptance of medicalized birth by Iranian women, some mothers still prefer natural delivery.

This study was one of the firsts to focus on medicalization of childbirth in Iran. The limitations of our study included the sampling method, which restricted generalizability of findings. We tried to control this limitation by using maximum variation. Also in this study, we only focused on mothers' perceptions. To gain a more comprehensive understanding of medicalized childbirth, perspectives of fathers and healthcare providers should be evaluated in future studies.

Childbirth has become increasingly medicalized in Iran and many Iranian mothers follow the medical approach, despite their inclination toward natural childbirth. Undoubtedly, medical approaches are necessary in specific circumstances, but overexpansion of medicalization interferes with mothers' decision-making about childbirth. In this study, we tried to provide a broad description of medicalization of childbirth in Iran using a qualitative inquiry. Health authorities can prevent the adverse effects of medicalized birth and encourage natural childbirth among women using the obtained findings. 


\section{Acknowledgements}

This study was supported by Mashhad University of Medical Sciences, Mashhad, Iran. We would like to thank all the mothers who participated in this study and helped us gathering data. We also appreciate the cooperation of Abou Ali Vedadhir at the Department of Demography and Population Studies, University of Tehran, Tehran, Iran.

\section{Authors' Contributions}

Sedigheh Sedigh Mobarakabadi contributed to the study design, data collection, data analysis and drafting of the manuscript. Khadijeh Mirzaie Najmabadi participated in the study design, analysis and drafting of the manuscript. Similarly, Mahmoud Ghazi Tabatabaie helped us with the study design, analysis and drafting of the manuscript.

\section{References}

1. Mrkic S, Johnson T, Rose M. World's Women 2010: Trends and Statistics. New York: United Nations Department of Economic and Social Affairs. 2010.

2. WHO UNICEF. UNFPA and The World Bank: Trends in maternal mortality: 1990 to 2008. Geneva: World Health Organization. 2010;17.

3. Wagner M. Fish can't see water: the need to humanize birth. Int J Gynaecol Obstet. 2001;75 Suppl 1:S25-37.

4. Conrad P. The Medicalization of Society: On the Transformation of Human Conditions into Treatable Disorders.: Johns Hopkins University Press; 2008.

5. Baker M. Childbirth Practices, Medical Intervention \& Women's Autonomy: Safer Childbirth or Bigger Profits? Womens Health Ur ban Life. 2005;4(2):27-43.

6. Christiaens W, Nieuwenhuijze MI, de Vries R. Trends in the medicalisation of childbirth in Flanders and the Netherlands. Midwifery. 2013;29(1):e1-8.

7. Smeenk AD, ten Have HA. Medicalization and obstetric care: an analysis of developments in Dutch midwifery. Med Health Care Philos. 2003;6(2):153-65.

8. Russo CA, Wier L, Steiner C. Healthcare Cost and Utilization Project (HCUP) Statistical Briefs. Rockville (MD): 2006. Hospitalizations Related to Childbirth, 2006: Statistical Brief \#71.

9. Hamilton BE, Martin JA, Ventura SJ. Births: preliminary data for 2009. Natl Vital Stat Rep. 2010;59(3):1-19.

10. Unicef [November 2014]; [cited 201426 March];Iran, Islamic Republic, Statistic. 2013 avilable from: $\{$ http://www.unicef.org/infobycountry/iran_statistics.html\}

11. Khodakarami N, Jannesari S. Mothers' knowledge of women's bill of right in pregnancy. Iran J Med Ethics History Med. 2009(2):51-8.

12. Bahadori F, Hakimi S, Heidarzade M. The trend of caesarean delivery in the Islamic Republic of Iran. East Mediterr Health J. 2013;19:S67-70.

13. Ghazi Tabatabaie M, Moudi Z, Vedadhir A. Home birth and barriers to referring women with obstetric complications to hospitals: a mixed-methods study in Zahedan, southeastern Iran. Reprod Health. 2012;9:5.

14. WHO . Health Systems Profile- Islamic Republic of Iran: Regional Health Systems Observatory- EMRO.: World Health Organization; 2006.

15. Torkzahrani S. Commentary: childbirth education in iran. J Perinat Educ. 2008;17(3):51-4.

16. Holloway I. Qualitative Research In Health Care.: Open University Press; 2005.

17. Morse JM, Field PA. Nursing Research: The Application of Qualitative Approaches.: Springer US;1996.

18. Creswell JW, Clark VLP. Designing and Conducting Mixed Methods Research.: SAGE Publications; 2007.

19. Hsieh HF, Shannon SE. Three approaches to qualitative content analysis. Qual Health Res. 2005;15(9):1277-88.

20. Speziale HS, Streubert HJ, Carpenter DR. Qualitative Research in Nursing: Advancing the Humanistic Imperative.: Wolters Kluwer Health/Lippincott Williams \& Wilkins; 2011.

21. Graneheim UH, Lundman B. Qualitative content analysis in nursing research: concepts, procedures and measures to achieve trustworthiness. Nurse Educ Today. 2004;24(2):105-12.

22. Polit DF, Beck CT. Essentials of Nursing Research: Appraising Evidence for Nursing Practice.: Wolters Kluwer Health; 2013.

23. McCourt C, Weaver J, Statham H, Beake S, Gamble J, Creedy DK Elective cesarean section and decision making: a critical review of the literature. Birth. 2007;34(1):65-79.

24. Awoyinka BS, Ayinde OA, Omigbodun AO. Acceptability of caesarean delivery to antenatal patients in a tertiary health facility in south-west Nigeria. J Obstet Gynaecol. 2006;26(3):208-10.

25. Walker R, Turnbull D, Wilkinson C. Increasing cesarean section rates: exploring the role of culture in an Australian community. Birth. 2004;31(2):117-24.

26. Kirkham M. The culture of midwifery in the National Health Service in England. J Adv Nurs. 1999;30(3):732-9.

27. Gamble JA, Creedy DK. Women's preference for a cesarean section: incidence and associated factors. Birth. 2001;28(2):101-10.

28. Lazarus ES. What do women want?: Issues of choice, control, and class in pregnancy and childbirth. Med Anthropol Q. 1994;8(1):2546.

29. Barker KK. A ship upon a stormy sea: the medicalization of pregnancy. Soc Sci Med.1998;47(8):1067-76.

30. Crossley ML. Childbirth, complications and the illusion ofchoice': A case study. Fem Psychol. 2007;17(4):543-63.

31. Beckett K. Choosing Cesarean Feminism and the politics of childbirth in the United States. Feminist Theory. 2005;6(3):251-75.

32. Statistical Center of Iran.. The President's Office Deputy of Strategic Planning and Control. National population and housing Census 2011.Tehran: Selected Findings; 2011. 